\title{
Ayudas públicas en Ecuador: análisis del mercado de comercialización de productos básicos agrícolas
}

\section{Public Aid in Ecuador: analysis of the market for agricultural commodities}

\section{Christian Narváez Barrera}

Investigador jurídico independiente

Abogado asociado de FERRERE Ecuador (equipo de Derecho

Corporativo)

Ciudad: Quito

País: Ecuador

\section{Antonella Cordero Porras}

Investigadora jurídica independiente

Abogada asociada en FERRERE Ecuador (equipo de Litigios)

Ciudad: Quito

País: Ecuador

Artículo original (investigación)

RFJ, No. 7, 2020, pp. 61-88, ISSN 2588-0837

RESUMEN: El presente trabajo tiene por objeto determinar si las medidas regulatorias implementadas de facto por el Estado ecuatoriano en el mercado de comercialización de productos básicos agrícolas, específicamente, en productos como el maíz, la leche cruda y el suero de leche, y el arroz, cumplen con los objetivos determinados por la Ley de Control de Poder de Mercado y su Reglamento; y, por lo tanto, pueden ser determinadas como ayudas públicas. Conforme se analiza, las ayudas públicas se pueden conferir por razones de interés social o público, o en beneficio de los consumidores; $y$, en el sector agrícola, a efectos impulsar la producción y transformación de alimentos, destinadas a garantizar la soberanía alimentaria $\mathrm{y}$ que se otorguen a pequeñas y medianas unidades de producción comunitaria y de la economía popular y solidaria. Se concluye que la Superintendencia de Control del Poder de Mercado es el órgano llamado al análisis de la eficiencia de las medidas teniendo en cuenta que, al no existir una política clara de competencia, actualmente, no se puede determinar si 
efectivamente estas medidas son económicamente eficientes; $\mathrm{o}$, si por el contrario, las políticas adoptadas en lugar de beneficiar a la economía nacional, la afectan negativamente.

PALABRAS CLAVE: Ayudas públicas, sector agrícola, mercado productos básicos ecuatorianos, fijación de precios.

ABSTRACT: The purpose of this paper is to determine if the regulatory measures implemented de facto by the Ecuadorian State for the commercialization of primary agricultural products, correctly, in products such as corn, raw milk and whey, and rice, comply with the objectives determined by the Organic Law for the Regulation and Control of Market Power and its Regulations. Furthermore, it can be determined as public aid. As analyzed, public aids can be conferred for reasons of social or public interest, or the benefit of consumers; and, in the Ecuadorian agricultural market in order to promote the production and transformation of food, aimed at guaranteeing food sovereignty and that are granted to small and mediumsized units of community production and of the famous and solidarity economy. It is concluded that the Superintendency of Control of Market Power is the public organism called to analyze the efficiency of the regulatory measures, taking into account that, since there is no clear competition policy, it cannot be determined whether these measures are indeed economically efficient; or on the contrary, the regulations harm the national economy.

KEYWORDS: Public aids, agricultural sector, ecuadorian primary products market, price-fixing.

\section{INTRODUCCIÓN}

Cuando pensamos en el modelo económico ecuatoriano, es usual asociarlo con un modelo extractivista; es decir, dependiente de la explotación de recursos naturales. $\mathrm{Si}$ bien, el término extractivismo se asocia directamente con los recursos naturales no renovables, este término no es ajeno a otros sectores de la economía como el sector agropecuario y ganadero. 
Ecuador, además de ser un país petrolero es un país fundamentalmente agrícola. (Pino Peralta, et al, 2018) El sector agropecuario, uno de los dos sectores primarios del Estado, desempeña un papel esencial en la economía ecuatoriana, llegando a aportar aproximadamente el 8\% del PIB nacional. (Camacho, 2008) Pero, este sector no solo es importante por los ingresos que genera; sino porque, de acuerdo al ex Ministerio de Agricultura, Ganadería, Acuacultura y Pesca MAGAP, ahora parte del Ministerio de Producción, Comercio Exterior, Inversiones y Pesca; es un sector llamado a responder las necesidades de supervivencia de la población ecuatoriana y la demanda internacional de alimentos. (Naranjo Bonilla, et al, 2016) Sin embargo, dado el carácter benefactor que asumió el Estado en la práctica, ¿se está cumpliendo este objetivo de una manera económicamente eficiente?

En el año 2012, el MAGAP impulsó la llamada "Revolución Agraria", que se fundamentó en un discurso basado en una alegada discriminación al sector campesino y en los problemas que atraviesa un país en vías de desarrollo como es el Ecuador. (Camacho, 2008) Así, el Estado asumió un rol protector del agro, y planteó la Revolución Agraria como una necesidad histórica, una "promesa y deuda al país" para erradicar las viejas estructuras consideradas un obstáculo para el desarrollo y la justicia social. (Vicuña Izquierdo, 2015)

Con fundamento en esta nueva lucha social, el Estado tomó a su cargo el fortalecimiento estructural del sector agropecuario, y decidió intervenir en él, con la consigna de erradicar la pobreza en el campo, garantizar la denominada seguridad alimentaria de la población, y "cristalizar las transformaciones que el país anhela en cuanto a las condiciones de producción y la dignificación del nivel de vida de los campesinos ecuatorianos". (Naranjo Bonilla, et al, 2016, p. 13) Así, el Estado concedió de facto, ayudas públicas en el sector agropecuario. A continuación, analizaremos algunas de las medidas adoptas en el mercado de comercialización de productos básicos agrícolas; y, el marco normativo relativo a las ayudas públicas en la legislación ecuatoriana. Este análisis se realiza con el propósito de determinar si estas medidas en efecto 
son equivalentes a ayudas públicas bajo la ley; y, cuál debería ser el rol que asuma la autoridad de competencia frente ellas; pues, la Superintendencia de Control del Poder de Mercado SCPM, es el órgano competente en materia de competencia, que se encuentra facultado para dilucidar si estas regulaciones guardan armonía con las normas ecuatorianas de competencia, y con ello, determinar si esta forma de intervencionismo favorece efectivamente al bienestar general de los ecuatorianos.

\section{REGULACIÓN DEL SECTOR AGROALIMENTARIO: EL MAIIZ; LA LECHE CRUDA Y SUERO DE LECHE; Y EL ARROZ.}

El Ecuador es un importante comercializador de commodities, como el maíz, la leche cruda y el arroz. A partir de la denominada "Revolución Agraria"; y, siguiendo los lineamientos de conceptos como la soberanía alimentaria, el Estado adoptó medidas regulatorias que, conforme se concluye en este análisis, han tenido un equivalente a una ayuda pública; no obstante, en el marco del derecho de competencia, permanece la interrogante relativa a si los efectos de estas regulaciones guardan armonía con las disposiciones de la Ley Orgánica de Regulación y Control del Poder de Mercado LORCPM; y, si han sido efectivamente para los consumidores, la libre competencia y otros agentes económicos que intervienen en el sector agroalimentario.

\subsection{Regulaciones impuestas sobre la comercialización de maíz amarillo duro}

El maíz amarillo duro es un producto indispensable para cubrir las necesidades de producción de la cadena productiva, por lo que, es uno de los productos más consumidos a nivel mundial. (Baca, 2016, p. 38) La comercialización del maíz no solo se da para el consumo humano directo, sino constituye alrededor del $60 \%$ al $75 \%$ de las dietas manejadas de animales de crianza, como son las aves de corral y cerdos, de los cuales se consume también su carne y productos derivados. De ahí la importancia de este producto en la elaboración de otros productos pecuarios, tales como la carne de cerdo, de pollo y huevos. (Baca, 2016, p. 38) En Ecuador, el maíz duro representa 
el 55\% de la formulación de alimentos para cerdos, y, el 75\% del consumo se concentra la industria avícola. (Diario el Telégrafo, 2020) Aproximadamente dos tercios de la producción mundial de maíz se destina a alimentos para animales. (FAO, 2010) En consecuencia, el maíz amarillo duro es la principal materia prima para la elaboración de la comida de pollos y cerdos, por lo tanto, es importante que su precio sea competitivo so pena de generar sobrecostos en la producción de derivados cárnicos, huevos, etc. (Zambrano, 2020)

Las principales regulaciones impuestas por el Estado a la comercialización de maíz son i) implementación de una política de absorción de la cosecha; y, ii) la fijación de precios de sustentación.

En el año 2011 el MAGAP suscribió el Convenio Interministerial entre este y el ex Ministerio de Industrias y Productividad MIPRO, para ejecutar el denominado Plan de Mejora Competitiva del Maíz, con el objeto de alcanzar el autoabastecimiento del maíz hasta el 2015, lo que se busca lograr a través del incremento de la productividad, modernización de la producción y comercialización, el aumento de la infraestructura de almacenamiento del maíz, entre otros. (Ministerio de Agricultura y Ganadería, 2011)

A partir del mes de abril de 2013, a través de la emisión del Acuerdo Ministerial No. 134 el MAGAP impuso la política de fijación del precio de sustentación del maíz con el objeto de que se fije un precio que cubra los precios de producción de este producto y que garantice un ingreso de los productores que permita adquirir la canasta del buen vivir. (Tamayo León, 2016) Actualmente, el precio del saco de maíz, con $13 \%$ de humedad y $1 \%$ de impurezas es de 14,60. (Diario el Telégrafo, 2020) Además, este Acuerdo qué determinó que las importaciones de maíz, entre otros productos, estén sujetas al requisito de absorción de la producción nacional, a efectos de garantizar que el autoabastecimiento de este producto, priorizando la producción nacional como política de Estado. (AM-134, 2013) El Artículo 3 de dicho Acuerdo Ministerial dispone: 
Las industrias fabricantes de balanceados y las industrias de producción de proteína animal, deberán dar prioridad a la producción doméstica comprando la totalidad de la cosecha nacional, tanto del ciclo de invierno como de verano, al precio de comercialización (PC) establecido técnicamente por el Estado, siempre que éste sea superior al precio mínimo de sustentación (PMS). En el caso que, el precio de comercialización (PC) esté por debajo del precio mínimo de sustentación (PMS), el MAGAP activará el PMS para la compra de la cosecha nacional, en reemplazo del PC. La obligación que tienen las industrias, para la compra de maíz amarillo, tendrá como máximo el volumen de sus consumos y se mantendrá, incluso cuando la producción nacional sea igual o superior a las necesidades de las industrias indicadas. (AM-134, 2013, art. 3)

El mecanismo funciona a través del otorgamiento de un cupo de importación de maíz, los importadores deben presentar una factura en donde se determine la cantidad comprada y el precio por el que adquirieron el producto nacional, para posteriormente, conferir un cupo limitado para la importación de maíz. (Tamayo León, 2016, p. 69) Además de conformidad con el Artículo 6 del Acuerdo Ministerial No. 134, con el fin de llevar un control adecuado y garantizar la transparencia del procedimiento, los gremios industriales y/o sus empresas afiliadas, así como las independientes, deberán registrar todas sus compras de maíz amarillo ante la Unidad de Registro de Transacciones y Facturación (URTF) del Ministerio. (AM-134, 2013, art. 6) Estas regulaciones, inciden directamente en la formación del precio de cultivo del maíz.

\subsection{Regulaciones impuestas sobre la comercialización de leche cruda y suero de leche}

De acuerdo con la Organización de las Naciones Unidas para la Alimentación y Agricultura FAO, hasta el 2011, los países que cuentan con mayor cantidad de productores de leche son Brasil (1.35 millones), Colombia (495 mil), Ecuador (301.500), Cuba (estimados 300 mil) y México (259 mil). (FAO-FEPALE, 2012, p. 33) Para 2012, la producción de la leche en Ecuador se concentraba en un $73 \%$ en la región de la sierra y comprendía 
mayormente pequeñas fincas productoras caracterizadas por ser de naturaleza familiar. (FAO-FEPALE, 2012, p. 42)

En el contexto de estas cifras, el 15 de marzo de 2013, el MAGAP y el MIPRO -ahora también parte del Ministerio de Comercio- emitieron el Acuerdo Interministerial 001-2013, por el cual se controló y reguló la cadena de producción de la leche y sus derivados en el Ecuador. Este acuerdo es aplicable a todos los productores de leche animal, incluyendo las especies bovina, caprina, ovina y bufalina la cual se destine al consumo humano y a la elaboración de productos derivados. Entre otras potestades, este acuerdo confirió al MAGAP la potestad para la fijación de precios de la leche cruda, con relación a la sustentación más calidad, por litro de leche cruda pagada en finca. (AI 001-2013, 2013, art. 10)

El 04 de septiembre de 2013, a la luz de las potestades otorgadas al MAGAP por el Acuerdo Interministerial 001-2013, entra en vigor el Acuerdo Ministerial 394-MAGAP, por el cual se fija el precio mínimo de sustentación al productor de leche cruda indexado en un $52.4 \%$ al precio de venta al público (PVP) del litro $(1,000 \mathrm{ml})$ del producto líder en el mercado lácteo interno, que es la leche UHT en funda.

El Acuerdo Ministerial 394 establece en su artículo 1 que el precio de sustentación al productor de leche cruda está indexado en un $52.4 \%$ al precio de venta al público (PVP) del litro (1,000 ml). En su Artículo 2, textualmente señala que: "Las industrias lácteas, y en general toda persona natural o jurídica que adquieran leche cruda están obligados a pagar en finca y/o centro de acopio a los productores de leche cruda el 52,4\% del precio de venta al público (PVP) vigente del litro leche UHT en funda $(1,000 \mathrm{ml})$ a nivel nacional más componentes, calidad higiénica y calidad sanitaria”. (AM-394, 2013, art. 2)

El artículo 11 del mencionado Acuerdo Ministerial establece una obligación a los compradores de leche cruda de informar al MAGAP -o quien haga sus veces-, sobre los resultados de la calidad de la leche cruda, así como el precio resultante de los mismos a cada uno de sus proveedores y a la Subsecretaría de Ganadería. 
Por otro lado, el Estado emitió otra regulación, contenida en el Acuerdo Ministerial No. 177 de 20 de septiembre de 2019 mediante el que, actualmente, el empleo y comercialización del lacto suero en su composición líquida se ve limitado al uso para la alimentación de animales y la elaboración de quesos de suero $^{1}$; mientras que en su presentación en polvo deshidratado, podrá ser empleado exclusivamente para la elaboración de bebidas compuestas con color, sabor, etiquetado y empaquetado diferente al de la leche cruda, para productos pulverizados, $\mathrm{y}$ para otros productos no sustitutos de la leche cruda. (AI-177, 2019, arts. 5, 6, 7, 8, 9, 10)

\subsection{Regulaciones impuestas sobre la comercialización del arroz}

De acuerdo con la Organización de las Naciones Unidas para la Alimentación y la Agricultura FAO, para el año 2013 se registró un total de 741 millones de toneladas métricas de la producción total de arroz en el mundo. (Tamayo León, 2016, p. 40) En el caso de Ecuador, la tendencia de producción ha sido variada con un pico de producción de hasta 1,7 toneladas métricas en el 2004. (Viteri y Zambrano, 2016, p. 11) La producción de éste producto en Ecuador se ha concentrado en las provincias de la costa, primordialmente, en Guayas, Manabí y Los Ríos, y su cultivo comprende una extensión estimada de 366.194 hectáreas. La importancia económica del arroz junto con otros cultivos agrícolas para 2016, sumó USD $\$ 2.290$ millones de dólares alcanzando una participación del 3,30\% del P.I.B., mientras que la molienda o pilado de arroz alcanzó los USD \$367,13 millones de dólares, con una participación del 0,53\% del P.I.B. (Corporación Financiera Nacional, 2018)

La primera medida regulatoria adoptada en el sector de comercialización de arroz que merece ser mencionada es la entrega por parte del Ministerio de Agricultura y Ganadería de los denominados "kits" que son paquetes tecnológicos agrícolas

1 Se permitirá la adquisición y utilización de suero de leche líquido proveniente de plantas lácteas que cuenten con certificado vigente de Buenas Prácticas de Manufactura registrado en la ARCSA para la elaboración de quesos de suero por parte de las plantas lácteas, las mismas que deberán contar con certificado vigente de Buenas Prácticas de Manufactura registrado en la ARCSA, previa autorización de la Agencia de Regulación y Control Fito y Zoosanitario. (AI-177, 2019, art. 7) 
para el cultivo de arroz. (Ministerio de Agricultura y Ganadería, 2018) Los paquetes tecnológicos de alto rendimiento están compuestos por semillas de alta calidad (certificadas), abonos edáficos y agroinsumos adecuados para reducir los costos de producción. (Ministerio de Agricultura y Ganadería, 2018) Además incluyen asistencia técnica, acceso a crédito y seguro agrícola. (Ministerio de Agricultura y Ganadería, 2018)

Por otro lado, el estado adoptó la medida de regulación del precio mínimo de sustentación del arroz mediante la adopción del Acuerdo Ministerial No. 069, expedido por parte del Ministerio de Agricultura y Ganadería desde el 25 de abril de 2019. En base a éste Acuerdo, se fijan dos categorías de precios: i) USD $\$ 29,00$ para la saca de 200 libras de arroz cáscara de grano corto; y, ii) USD $\$ 31,00$ para la saca de 200 libras de arroz cáscara grano largo. (AM-69, 2019, Art. 1 y 2) Sobre la base de estos precios, inicia la cadena productiva del arroz la cual, de acuerdo con la Corporación Financiera Nacional CFN, se comprende de siete etapas hasta llegar al consumidor final: empezando por el cultivo en pequeña, mediana y gran escala, seguido por el manejo y almacenamiento de la cosecha; luego, el arroz pasa por un proceso de secamiento, limpieza y trillado. El cuarto eslabón, comprende su almacenaje y acopio en mediana y grande escala, previo a ser distribuido al por mayor y menor a los supermercados y tiendas de barrio hasta llegar al consumidor final. (Corporación Financiera Nacional, 2018)

\section{LAS AYUDAS PÚBLICAS Y EL SECTOR AGRÍCOLA}

Una vez que hemos determinado algunas de las regulaciones dictadas por el Estado que afectan al mercado de comercialización de bienes agroalimentarios primarios, específicamente del maíz, la leche cruda y suero de leche; y, el arroz -que en consecuencia, afectan también el mercado aguas arriba de estos productos- analizaremos el marco general y deber ser de las ayudas públicas en el sector agrícola.

Siguiendo el criterio de Blanquer, las ayudas públicas abarcan todas las medidas de promoción del Estado, que implican otorgar una ventaja o beneficio económico, aunque no comporten la entrega de una cantidad de dinero. (Blanquer, 
2010, p. 17) De ahí, que las ayudas públicas, sean un mecanismo a través del cual el Estado otorgue beneficios a determinados sectores de la economía, bajo distintas formas, de manera directa o indirecta, por razones de interés social o públicas. Sin embargo, estos beneficios tienen un límite, pues como regla general, no podrían afectar a los consumidores, al derecho a libre competencia, y/o a otros agentes económicos que intervienen en el mercado.

Ahora bien, el sector agropecuario cuenta con una regulación sectorial y una política pública consolidada; y, por lo tanto, no le aplican irrestrictamente las leyes y política de competencia, que en el caso del Ecuador son relativamente recientes y se encuentran en proceso de desarrollo. Por ello, previo a analizar cuál es la tendencia en el Ecuador, es necesario considerar que la Unión Europea y los Estados Unidos, también tienen un sistema de regulación especial/sectorial del sector agrícola y sus políticas; sin embargo, sin perjuicio de esta "especialidad sectorial" los sistemas de Estados Unidos y Europa han logrado que las regulaciones sean capaces de proteger tanto a los agricultores, como la finalidad que persiguen las normas y políticas de competencia, asegurando que, en caso de ser restringidas o moderas por dichas regulaciones, su finalidad y objetivos no se vean defraudados ilegítimamente.

\subsection{Las ayudas públicas en la Unión Europea}

El caso de la Unión Europea, se han adoptado normas sectoriales que han hecho aplicables de forma limitada las normas generales relativas a la concesión de ayudas públicas "generales", a las ayudas públicas en el sector agropecuario. Incluso las normas que establecen los criterios para determinar si cierta medida perjudica al mercado, no aplican a ayudas concedidas a determinadas empresas que operan en la producción primaria de productos agrícolas. (Icaza Ortiz, 2017, p. 52)

Se debe considerar sin embargo, que en el caso de la Unión Europea, nos encontramos frente a un mercado abierto entre sus estados miembros, por ello por regla general se considera que las ayudas públicas del Estado son incompatibles 
con la competencia entre los operadores de mercado que impulsa la comunidad europea, pues esas ayudas distorsionarían la igualdad de quienes compiten en los mercados económicos, en la medida en la que afecten los intercambios comerciales entre los estados miembros y que bajo cualquier forma falseen, o amenacen con falsear la competencia del mercado abierto de la Unión Europea. (Blanquer, 2010, pp. 1014 y 1019) Sin embargo, debe tenerse en cuenta que, dado el desarrollo del derecho comunitario, las regulaciones del sector agrícola por regla general no afectan a la economía comunitaria, cuya tutela es uno de los fines prioritarios de la Unión Europea.

\subsection{La política norteamericana en materia de ayudas públicas}

En el caso de los Estados Unidos, ha ocurrido que, si bien se ha excluido al sector agrícola de la aplicación de las normas antitrust, se lo ha hecho con un enfoque que permita el bienestar de los asociados de los gremios de agricultores, pero de tal manera que no afecten negativamente el mercado. Así, en un inicio, el mismo senador Sherman intento excluir de manera expresa del Sherman Act, a los acuerdos o organizaciones que se realizan entre personas del sector agrícola que tengan por objeto mejorar los precios de los productos; sin embargo, esta propuesta no se incluyó en la ley. (Icaza Ortiz, 2017, p. 52) Fue recién a través de la Ley Clayton de 1914, que se determinó que las normas antitrust no se pueden aplicar al funcionamiento de organizaciones en sectores de agricultura, ni a sus miembros, siempre y cuando busquen la consecución de los fines establecidos en dicha ley. (Icaza Ortiz, 2017, p. 52)

Finalmente con la ley Capper - Volstead, se reguló las actividades de los gremios agrícolas y a través de la Agricultural Marketing Agreement Act se permitió que la Secretaría de Agricultura de los Estados Unidos pueda celebrar; por un lado, acuerdos con los miembros de asociaciones agrícolas, a efectos de que voluntariamente los productores de bienes agrícolas pacten condiciones para su comercialización; o, para emitir las denominadas "ordenes al mercado" que son normas de carácter general y obligatorio para ciertos grupos de productores de bienes, en las zonas específicamente delimitadas en la orden. A 
través de estas figuras en Estados Unidos se pueden establecer incluso límites a la calidad y cantidad de los bienes agrícolas. (United States vs. Borden; United States vs. Maryland \& Virginia Milk Producers Association, 1960, p. 247)

A pesar de lo señalado, en Estados Unidos es claro que, las conductas anticompetitivas no cubiertas por un acuerdo o una orden al mercado válida, si pueden ser sancionadas, pese a que estén excluidas de la aplicación de las normas antitrust; y además, que las conductas anticompetitivas que realicen con personas no productores están indiscutiblemente sujetas a las normas antitrust. (United States vs. Borden; United States vs. Maryland \& Virginia Milk Producers Association, 1960, p. 247) La jurisprudencia estadounidense ha dejado precedentes claros en relación a cómo se desarrolla y organiza el sector agrícola de manera armónica con la libre competencia, pues de lo antes mencionado es claro que los gremios del sector agrícola tienen poder de negociación colectivo, pueden decidir sobre el precio de sus productos, y pueden usar su poder para salvaguardar el mercado de los productos que comercializa, pero que esto no puede utilizarse para falsear o distorsionar la competencia. (Icaza Ortiz, 2017, p. 52) Esto es, existe una medida perfecta entre el poder de decisión del sector, sin mayor injerencia del Estado, que ejerce su poder regulatorio únicamente para determinar que estas conductas no tengan efectos anticompetitivos.

Conforme indicamos previamente, en el Ecuador las normas de derecho de competencia son muy recientes, y no existe una verdadera política de competencia impulsada por la Junta de Regulación que logre -como en los Estados Unidos y Europa- armonizar la política agrícola impulsada por el Ministerio de Producción, Comercio Exterior, Inversiones y Pesca, con la política de competencia ecuatoriana que se encuentra en camino de desarrollo. De ahí, la importancia de partir de un análisis de la normativa ecuatoriana en materia de competencia, específicamente en relación con las ayudas públicas, para poder analizar la posibilidad de que ésta guarde armonía con la política pública agropecuaria ecuatoriana. 


\subsection{El régimen de las Ayudas Públicas en el Ecuador}

La Constitución de la República reconoce el derecho a la libre empresa y la libre competencia, y determina que el Estado impulsará y velará por el comercio justo como medio de acceso a bienes y servicios de calidad, que minimice las distorsiones de la intermediación y promueva la sustentabilidad; y que, asegurará la transparencia y eficiencia en los mercados, fomentando la competencia en igualdad de condiciones y oportunidades. (CRE, 2008, art. 335) Por otro lado, la Constitución define al sistema económico ecuatoriano como "social y solidario"; y, en su Artículo 283 dispone:

El sistema económico es social y solidario; reconoce al ser humano como sujeto y fin; propende a una relación dinámica y equilibrada entre sociedad, Estado y mercado, en armonía con la naturaleza; y tiene por objetivo garantizar la producción y reproducción de las condiciones materiales e inmateriales que posibiliten el buen vivir. (CRE, 2008, art. 283)

En razón de aquello, la Constitución ha determinado que la política económica tenga objetivos tales como: asegurar una adecuada distribución del ingreso y la riqueza nacional, incentivar la producción nacional, la productividad y competitividad sistémicas; asegurar la denominada soberanía alimentaria, mantener la estabilidad económica, entendida como el máximo nivel de producción y empleo sostenibles en el tiempo, e impulsar un consumo social y ambientalmente responsable. (CRE, 2008, art. 284) Por otro lado, la Constitución ha basado la política comercial ecuatoriana en el desarrollo y fortalecimiento de los mercados internos, con base al Plan Nacional de Desarrollo (Plan Nacional del Buen Vivir); fortalecer el aparato productivo y la producción nacionales; contribuir a que se garantice la soberanía alimentaria y se reduzcan las desigualdades internas; entre otros. (CRE, 2008, art. 304) Finalmente la Constitución en su Artículo 335 dispone:

El Estado regulará, controlará e intervendrá, cuando sea necesario, en los intercambios y transacciones económicas; y sancionará la explotación, usura, acaparamiento, simulación, intermediación especulativa de los bienes y servicios, así como 
toda forma de perjuicio a los derechos económicos y a los bienes públicos y colectivos.

El Estado definirá una política de precios orientada a proteger la producción nacional, establecerá los mecanismos de sanción para evitar cualquier práctica de monopolio y oligopolio privados, o de abuso de posición de dominio en el mercado y otras prácticas de competencia desleal. (CRE, 2008, art. 335)

Así, vemos que la mente extractivista estatal, de explotación y comercialización de materias primas, también se encuentra muy presente en otros sectores de la economía; pues, de las normas antes citadas, se desprende que la Constitución estableció los cimientos de una política que sostiene, entre sus ejes principales, el impulso del máximo nivel de producción nacional y el fortalecimiento del aparato productivo nacional. Esta regulación constitucional ha abierto la puerta a que, a pesar de que se reconozca constitucionalmente la libre empresa y competencia, el Estado adopte un rol intervencionista, que muchas veces puede llegar a limitar estos derechos.

A la luz de este modelo constitucional es que el Estado, a través de regulaciones sectoriales, ha conferido de facto ayudas públicas, sin que exista un análisis de sus efectos sobre la libre competencia; esto, debido a que, como indicamos anteriormente, la normativa del derecho de competencia es bastante reciente, con la publicación de la LORCPM recién en octubre del año 2011, como punto de partida para analizar si estas regulaciones, son o no amistosas con la libre competencia.

La LORCPM determina que será admisible el establecimiento de restricciones a la competencia mediante resolución motivada de la Junta de Regulación, por razones de interés público, en cualquier sector de la economía nacional, en los siguientes casos:

a. Para el desarrollo de un monopolio estatal a favor del interés público,

b. Para el desarrollo de sectores estratégicos,

c. Para la prestación de servicios públicos,

d. Para el desarrollo tecnológico e industrial de la economía nacional, 
e. Para la implementación de iniciativas de acción afirmativa a favor de la economía popular y solidaria. (LORCPM, 2011, art. 28)

Entonces, de acuerdo con la LORCPM, las ayudas públicas necesariamente se encuentran ligadas a razones de interés público, cuando se generen beneficios específicos, concretos y significativos para la satisfacción del interés general, en el ámbito o industria en la que se establezcan, se incremente la eficiencia, y se generen beneficios a favor de los consumidores o usuarios que justifiquen su necesidad.

Por otro lado, el Artículo 34 del Reglamento a la Ley Orgánica de Regulación y Control del Poder de Mercado (2012) dispone que:

Se entenderá que constituye ayuda pública, la ayuda concedida por el Estado o mediante la utilización de recursos públicos, que (i) suponga o pueda suponer una ventaja económica para uno o varios operadores, que no habrían obtenido en el ejercicio normal de sus actividades; (ii) tenga un carácter selectivo para determinados operadores económicos o sectores.

Específicamente, en el sector agrícola se podrán otorgar ayudas públicas, por razones de interés social o público, o en beneficio de los consumidores, de acuerdo con lo dispuesto en el Artículo 29 (h) de la LORCPM (2011), que señala:

Se podrán otorgar ayudas por el Estado o mediante la utilización de recursos públicos, por el tiempo que fuere necesario, por razones de interés social o público, o en beneficio de los consumidores. Procederá el otorgamiento de ayudas públicas en los siguientes casos: [...]

h) Las ayudas orientadas a impulsar la producción y transformación de alimentos, destinadas a garantizar la soberanía alimentaria y que se otorguen a pequeñas y medianas unidades de producción comunitaria y de la economía popular y solidaria. (art. 29) 
De acuerdo con lo dispuesto en el Artículo 31 de la LORCPM, la Superintendencia de Control del Poder de Mercado, tiene la facultad de evaluar las ayudas públicas, a efectos de determinar si estas cumplen o no con los objetivos establecidos en la norma antes citadas. Así, el mencionado Artículo dispone:

La Superintendencia de Control del Poder de Mercado examinará permanentemente las ayudas públicas conferidas en virtud de las disposiciones de este capítulo, y evaluará que cumplan con los fines que motivaron su implementación. Salvo en los casos en que no se trate de actividades o sectores económicos reservados exclusivamente al Estado, la Superintendencia de Control del Poder de Mercado propondrá las medidas apropiadas para el desarrollo progresivo del régimen de competencia en las actividades o los sectores beneficiarios.

Si la Superintendencia comprobare que una ayuda otorgada por el Estado o mediante recursos públicos no cumple con el fin para el cual se otorgó, o se aplica de manera abusiva o es contraria al objeto de esta Ley, mediante informe motivado, instará y promoverá su supresión o modificación dentro del plazo que determine. (LORCPM, 2011, art. 31)

De acuerdo con esta norma, la Superintendencia de Control del Poder de Mercado (SCPM), además de tener la facultad de revisar las ayudas públicas conferidas por el Estado, tiene una obligación de evaluarlas permanentemente. Consideramos que esta es una facultad con una utilidad práctica increíble, pues su correcta aplicación permitiría que la Superintendencia pueda lograr el objetivo de armonizar las regulaciones estatales dictadas en el sector agropecuario, con las normas de libre competencia. Además, la Superintendencia tiene la facultad de proponer las medidas que considere apropiadas para el desarrollo progresivo del régimen de competencia, incluso en los sectores económicos que se encuentran reservados exclusivamente para el Estado (i.e. Sectores Estratégicos). Finalmente, es de vital importancia recalcar que la SCPM tiene la facultad de determinar si una ayuda pública cumple o no con el fin para el cual se otorgó, se aplica de manera abusiva o es contraria al objeto de la LORCPM; 
y, en virtud de aquello que puede impulsar su supresión o su modificación.

Sentado el marco normativo de cómo debería funcionar el otorgamiento de ayudas públicas por parte del Estado, analizaremos si las regulaciones estatales en el mercado de comercialización de maíz, leche cruda y arroz, y el mercado aguas arriba de los mismos productos, descritas en la Sección II de este análisis, son consistentes con la normativa ecuatoriana; y además, logran una armonía con el derecho a la libre competencia.

\section{LAS REGULACIONES ESTATAL DE LA COMERCIALI- ZACIÓN DE PRODUCTOS AGROALIMENTARIOS PRI- MARIOS TIENEN EL EFECTO DE AYUDAS PÚBLICAS: RECOMENDACIONES}

A continuación, describiremos cómo es que las regulaciones impuestas por el Estado en la comercialización del maíz, leche cruda y arroz; son medidas equivalentes a ayudas públicas bajo la ley ecuatoriana; y cómo estas regulaciones indudablemente afectan el mercado aguas arriba de estos productos.

\subsection{El caso del Maíz}

El caso del maíz es un ejemplo claro de una medida adoptada por el Estado que tiene un efecto equivalente a una ayuda pública conferida a favor del sector agrícola, específicamente en beneficio de los productores de maíz y que, además, genera un impacto en el mercado aguas arriba, como es el mercado de comercialización local de proteína animal.

Consideramos que las regulaciones a la comercialización de maíz suponen necesariamente una ventaja económica para los productores de maíz, ya que los productores del mercado local de proteína animal; esto es, productores de carne de cerdo, carne de pollo y huevos están obligados a adquirir el maíz -que es la materia prima principal para alimentar sus animales de crianza- de productores locales, dado la política de absorción de la cosecha local del producto. Esta regulación a su vez implica 
una restricción en el mercado local de proteína animal, pues los productores dentro de este mercado se encuentran restringidos de importar maíz del extranjero a pesar de que los precios del maíz en el mercado ecuatoriano son mucho mas elevados que la mayoría de los precios internacionales. (Baca, 2016, p. 42)

Por ello, al existir una ventaja económica para los productores de maíz, esta se enmarca en el requisito establecido en Artículo 31(1) del RLORCPM. Además, esta medida tiene un carácter selectivo para un determinado sector económico que es el sector de comercialización agroalimentaria, específicamente del maíz. Por lo tanto, esta medida también cumple con el segundo requisito establecido en el Artículo 31(2) del RLORCPM, y debería considerarse equivalente a una ayuda pública, a pesar de no haber sido dictada por la Junta de Regulación.

Además, se debe tener en consideración que esta medida adoptada por el Estado, externa y ajena a las reglas de la libre competencia, implica una restricción clara en el mercado aguas arriba del producto. Según datos de la Asociación de Productores de Alimentos Balanceados (APROBAL), la Corporación Nacional de Avicultores del Ecuador (CONAVE), la Asociación de Porcicultores del Ecuador (ASPE) y la Asociación de Fabricantes de Alimentos Balanceados (AFABA) el precio del maíz debería reducirse para no perder competitividad. Estos gremios sostienen que el precio vigente en el año 2019 del maíz (US\$15,25) era 50\% más alto que en Colombia y Perú, lo que resta competitividad al sector. (Diario El Comercio, 2020) Asimismo, sostienen que, durante las negociaciones con los países de la Alianza del Pacífico, los precios de las proteínas en el Ecuador son los más elevados de la región, debido al precio del maíz.

Por otro lado, estos gremios sostienen que en el 2019 los precios de la libra de carne de pollo cayeron un 5\% más, en relación al 2018, y que esto llevó a que el sector avícola tenga los peores resultados económicos de los últimos 10 años; y que, en el caso del cerdo, el precio cayó hasta en un $25 \%$ por debajo del costo de producción, lo que ocasionó graves pérdidas a los 
productores, sobre todo del estrato familiar que aportan con el $30 \%$ de la producción.

Por lo tanto, conforme se explica en las conclusiones de este análisis, la SCPM tendría la facultad clara, bajo el artículo 31 de la LORCPM, de determinar si estas medidas son económicamente eficientes y guardan armonía con la ley y la política de competencia -en desarrollo- o, en su defecto, si estas medidas son equivalentes a una ayuda pública prohibida, o deberían ser moderas a efectos de que cumplan con los objetivos establecidos en el Artículo 29, literal (h) de la misma ley.

\subsection{El caso de la leche cruda}

El caso de la fijación del precio de sustentación de la leche cruda es, de hecho, una ayuda pública, pues, así como en el caso del maíz, cumple con los criterios establecidos en los numerales (1) y (2) del Artículo 31 del RLORCPM, por encontrarse enfocada en brindar una ventaja económica a favor de uno o varios operadores, que no la habrían obtenido en el ejercicio normal de sus actividades y, además, está dirigida únicamente al sector ganadero, y genera efectos en el mercado aguas arriba del mercado de leche cruda así como en el de otros productos de la industria de lácteos. Además, se debe tener en consideración que, a partir de la emisión del Acuerdo Ministerial No. 394, el MAGAP controla a la industria de producción de lácteos en general -que incluye venta de productos que no necesariamente utilizan como materia prima la leche crudaa efectos de que estas informen sobre sus adquisiciones de leche cruda.

La fijación del precio de la leche cruda va a tener efectos en los mercados aguas arriba de la cadena productiva. Según un estudio de mercado realizado por la Superintendencia de Control de Poder de Mercado, los circuitos comerciales estarían conformados, en el primer nivel, por el productor, quien deberá cumplir con todos los procesos sanitarios para la obtención de un producto de calidad (Agrocalidad Resolución 41, 2017); en segundo nivel, la venta de la leche se realizaría a intermediarios y centros de acopio, así como a detallistas y comerciantes 
informales de productos elaborados artesanalmente. Como tercer eslabón, se encuentran las industrias lácteas que procesan la leche para elaborar productos como quesos, leche en funda, en cartón, en polvo, yogurt, etc., los cuales abastecen a los supermercados; y, estos a su vez, llegan a manos del consumidor final. ${ }^{2}$

Por otro lado, la prohibición de uso y comercialización del lacto suero líquido, también constituye de hecho una ayuda pública por cuanto beneficia a quienes comercializan leche cruda, lo que obliga a las industrias que comercializan productos lácteos a adquirir leche cruda, leche larga vida - UHT, o leche pasteurizada modificada -que tienen costos mucho más altos- lo que encarece los costos de producción de ciertos productos. Hasta la emisión de esta prohibición, los operadores económicos compuestos por industrias procesadoras de leche empleaban y comercializaban el lacto suero líquido ${ }^{3}$, como un sustituto de la leche cruda para la elaboración de productos a base de suero de leche. El suero de leche se utiliza para la elaboración de bebidas lácteas, quesos tipo ricota, helado, chocolate; pero, también para la elaboración de productos pertenecientes a mercados diametralmente distintos al mercado de comercialización de lácteos, como para la elaboración de jabones íntimos, bebidas energizantes, entre otros. (González y Alvarado, 2019)

A raíz de la promulgación del Acuerdo Interministerial No. 17 el 20 de septiembre de 2019, la industria de producción de lácteos sufrió un impacto en el precio de comercialización de productos elaborados con lacto suero en polvo que, según miembros del sector ganadero, incrementó a raíz de la

2 La Superintendencia de Control de Poder del Mercado realizó el estudio de mercado del Sector de la Leche en el Ecuador, con el objetivo de: "conocer la dinámica y estructura del sector lechero en el Ecuador, y poder identificar las posibles distorsiones en este mercado"; así como también "determinar si existen las buenas prácticas comerciales en este importante sector de la economía, en los diferentes eslabones que forman parte de la cadena productiva, específicamente si se respeta el precio mínimo de sustentación más el pago por los componentes, calidad higiénica y calidad sanitaria." (Alvarado, 2012, p. 32)

3 Un subproducto derivado de la cadena productiva de la leche que se emplea en la elaboración de productos alternativos, pero no sustitutos, como el yogurt, los quesos artesanales, la leche en polvo, las proteínas y comida para bebés. (El Comercio, 2019) 
prohibición, por cuanto el proceso industrial se duplica: deben deshidratar el lacto suero, para que sea comercializado; y, posteriormente, vuelva a ser hidratado. (González y Alvarado, 2019) En este sentido, muchas compañías han optado por la importación de lacto suero en polvo ya que no cuentan con los insumos industriales para su deshidratación, encareciendo a la larga el producto para el cliente final. (González y Alvarado, 2019)

Dados los efectos de las medidas adoptadas por el Estado en la comercialización de la leche cruda, la SCPM tendría la potestad, a la luz el artículo 31 de la LORCPM, de determinar si esta medida es económicamente eficiente y armoniosa con la ley y la política de competencia.

\subsection{El caso del arroz}

La implementación de precios mínimos de sustentación para el cultivo del arroz, así como la implementación de medidas como la entrega de "kits agrícolas" a los gremios de productores en el Ecuador, podrían enmarcarse como una ayuda pública, por su efecto, a la luz de la regulación de competencia establecidas por la LORCPM y su Reglamento, en la medida en que se ha sectorizado hacia mercado de producto del arroz, cumpliendo con lo determinado en los numerales (1) y (2) del Artículo 31, así como lo previsto en el Artículo 34 del RLORCPM ya que, sin lugar a dudas, suponen una ventaja económica para los productores de arroz, en la medida en que asegura su acceso a tecnología, inversión en caso de pérdida de los cultivos, sea por motivos climáticos o enfermedades y/o plagas. (Ministerios de Agricultura y Ganadería, 2019)

Esta ventaja se ve refleja en el precio final de comercialización del arroz hacia el consumidor final. Como lo manifiestan Viteri y Zambrano, un estudio de mercado que partió de la hipótesis de que los consumidores resultan perjudicados por la evolución de los precios de arroz debido a que coexisten situaciones de precios bajos en origen con altos precios en destino (Viteri y Zambrano, 2016, p. 12), presentó una correlación positiva significativa entre el precio 
de productor versus el precio del consumidor, confirmándose la hipótesis objeto del estudio. El mismo resultado, se manifestó con los precios agrarios percibidos y pagados, los agricultores perciben bajos precios por sus productos, pero los precios de los consumidores finales no están acordes con dichos precios. (Viteri y Zambrano, 2016, p. 14)

Consideramos que la SCPM es el órgano llamado al análisis de la eficiencia de las medidas teniendo en cuenta que el precio del arroz, según lo afirman las asociaciones gremiales, no es competitivo. Por ende, las empresas privadas y las piladoras optan por negociar el precio por debajo de lo establecido, contra la amenaza de comprar arroz que ha ingresado de contrabando de otros mercados, a precios más económicos, como es el arroz peruano. (Diario El Comercio, 2017) Éste fenómeno, podría incidir en que las medidas de no cumplan con el objetivo establecido en el literal (h) del Artículo 29 del RLORCPM (2012), esto es: "ayudas orientadas a impulsar la producción y transformación de alimentos, destinadas a garantizar la soberanía alimentaria [...] en beneficio de los consumidores."

\section{CONCLUSIONES}

En relación con los efectos de estas medidas equivalentes a ayudas públicas han tenido en el mercado; consideramos que, la autoridad de competencia, SCPM, bajo la LORCPM y su Reglamento, tiene la facultad de analizar si estas medidas cumplen o no con los fines por los cuales el Estado puede conferir ayudas públicas. Es más, es fundamental entender la eficiencia económica de estas regulaciones sectoriales que, seguramente, están afectando negativamente la cadena de producción de la industria porcícola, avícola, entre otras.

Conforme se analizó, las ayudas públicas se pueden conferir por razones de interés social o público, o en beneficio de los consumidores; y, en el sector agrícola, a efectos impulsar la producción y transformación de alimentos, destinadas a garantizar la soberanía alimentaria y que se otorguen a pequeñas y medianas unidades de producción comunitaria y de la economía popular y solidaria. Dado que estas medidas constituyen un factor externo, ajeno a las fuerzas naturales 
del mercado, necesariamente lo afectan. Esta afectación puede ser en su beneficio, al responder en realidad a intereses que legítimamente requieren protección; o también, pueden resultar en un perjuicio grave y llegar a obstaculizar, dificultar o falsear la competencia.

Para ello, primero es indispensable que las autoridades de competencia continúen desarrollando una política clara de competencia que pueda permitir un mejor control de las regulaciones emitidas por el Estado, no solo en el sector agroalimentario sino en otros sectores de la economía. Solo con una política clara de competencia se puede armonizar la normativa en esta materia, con las regulaciones y políticas en otros sectores de la economía.

Es claro que el Estado tiene una mente extractivista incluso en relación con las políticas implementadas en el sector agroalimentario, mediante el que pretende potencializar y priorizar la producción local, a toda costa. Al no haber una política clara de competencia, actualmente no se puede determinar si efectivamente estas medidas son económicamente eficientes; o, si por el contrario, las políticas adoptadas en lugar de beneficiar a la economía nacional, la afectan negativamente; $\mathrm{y}$, sin un análisis de estas políticas y regulaciones por parte de la autoridad de competencia, tampoco se puede tomar decisiones para que estas regulaciones sean modificadas o adaptadas de tal manera que sean beneficiosas para el mercado.

Finalmente, es indispensable manifestar que con el objeto de lograr una medida justa entre los efectos positivos y negativos que puede generar el otorgamiento de una medida equivalente a una ayuda pública por parte del Estado, la SCPM haga uso de las herramientas legales a las que tiene acceso. Entre estas, que haga uso de la facultad de revisar estas regulaciones dictadas por el Estado en el sector agrícola/agroalimentario en aras de armonizar las regulaciones con las normas y política de competencia, y proponga las medidas que considere apropiadas para que estas medidas garanticen la eficiencia económica y en general el beneficio de los ecuatorianos y ecuatorianas 


\section{.REFERENCIAS BIBLIOGRÁFICAS \\ (Publicaciones, cuerpos legales y jurisprudencia)}

\section{Publicaciones}

Alvarado, R. (2012). Estudio de Mercado del Sector de la Leche en el Ecuador. Quito: Superintendencia de Control de Poder del Mercado.

Baca, L. (2016). La producción de maíz amarillo en el Ecuador y su relación con la soberanía alimentaria. (Tesis de grado). Pontificia Universidad Católica del Ecuador: Quito, Ecuador.

Blanquer, D. (2010). Derecho Administrativo, tomo 2. Valencia: Tirant Lo Blanch.

Camacho, E. (2008). Estructura del Sector Agropecuario, según el enfoque de las características del productor agropecuario $y$ de las unidades de producción agropecuaria. Quito: Instituto Nacional de Estadística y Censos. Recuperado de: https://www.ecuadorencifras.gob.ec/documentos/ web-inec/Bibliotecas/Estudios/Estudios Economicos/Evolucion_de_la_indus_Alimen_ Beb_2001-2006/Estruc_Sector_Agropecuario.pdf

Corporación Financiera Nacional. (2018). Ficha Sectorial: Arroz. Quito: Subgerencia de Análisis e Información de la Corporación Financiera Nacional. Recuperado de: https://www.cfn.fin.ec/wp-content/ uploads/2018/04/ Ficha-Sectorial-Arroz.pdf

Diario El Comercio. (11 de octubre de 2017). Mercado saturado y contrabando afecta el precio del arroz. Diario El Comercio. Recuperado de: https://www.elcomercio. com/actualidad/mercado-saturado-contrabandoprecio-arroz.html 
Diario El Comercio. (24 de septiembre de 2019). 56 productos nacionales utilizan el lactosuero en estado líquido. Diario El Comercio. Recuperado de: https://www. elcomercio.com/actualidad/productos-nacionaleslactosuero-liquido.html

Diario El Comercio. (07 de enero de 2020). Industriales sugieren fijar el precio del maíz en USD13,21; productores quieren que se mantenga en USD 15,25. Diario El Comercio. Recuperado de: https://www. elcomercio.com/ actualidad/precio-maiz-productoresmag-cosecha. html

Diario el Telégrafo. (10 de enero de 2020). "En 14,60 se fija el precio del saco de maíz para este año." Diario el Telégrafo. Recuperado de: https://www.eltelegrafo. com.ec/ noticias/economia/4/fija-precio-saco-maizpara-ano

FAO-FEPALE. (2012). Situación de la Lechería en América Latina y el Caribe en 2011. Chile: Oficina Regional de la FAO para América Latina y el Caribe, División de Producción y Sanidad Animal.

González, P., y Alvarado, P. (24 de septiembre de 2019). 56 productos nacionales utilizan el lactosuero en estado líquido. Diario El Comercio. Recuperado de: https://www. elcomercio.com/actualidad/productosnacionales-lactosuero-liquido.html

Icaza Ortiz, D. (2017). Las ayudas públicas en el sector agroalimentario y su afectación al derecho de competencia. (Tesis de Maestría). Quito: Pontificia Universidad Católica del Ecuador.

Ministerio de Agricultura y Ganadería. (2011). Resultados del plan de mejora competitiva de la cadena del maíz amarillo duro. Quito: Ministerio de Agricultura y Ganadería. Recuperado de: https://www.agricultura.gob.ec/ magap-cuenta-con-un-plan-de-mejora-competitiva-delacadena-del-maiz-amarillo/ 
Ministerio de Agricultura y Ganadería. (2018). MAG entrega kits para el cultivo de arroz, en Loja. Quito: Ministerio de Agricultura y Ganadería. Recuperado de: https://www. agricultura.gob.ec/mag-entrega-kits-para-el-cultivodearroz-en-loja/

Ministerios de Agricultura y Ganadería. (2019). Más de 31 mil agricultores reciben kits agrícolas para mejorar la producción. Recuperado de: https://www.agricultura. gob.ec/ mas-de-31-mil-agricultores-reciben-kitsagricolas-para-mejorar-la-produccion/

Naranjo Bonilla, M. et al. (2016). La Política Agropecuaria Ecuatoriana. Hacia el Desarrollo Territorial Rural sostenible 2015-2025. Quito: Ministerio de Agricultura, Ganadería, Acuacultura y Pesca, ISBN 978-9942-22019-6.

Organización de las Naciones Unidas para la Alimentación y la Agricultura FAO. (2010). Nutrición Vegetal Maíz. Recuperado de: https://www.yara.com.ec/nutricionvegetal/maiz/mercados-del-maiz/

Pino Peralta, S., et. al. (2018). Aporte del Sector Agropecuario en la Economía del Ecuador. Análisis crítico de su evolución en el período de dolarización Años 2000-2016. Revista Espacios, (p. 7). Recuperado de: https://www. revistaespacios.com/a18v39n32/a18v39n32p07.pdf

Tamayo León, D. (2016). La transmisión de precios en el mercado agrícola: El caso del arroz y maíz en Ecuador, período 20002014. (Tesis de grado). Quito: Pontificia Universidad Católica del Ecuador.

Vicuña Izquierdo, L. (28 de enero de 2015). Revolución Agraria, Necesidad Histórica. Diario El Telégrafo. Recuperado de: https://www.eltelegrafo.com.ec/noticias/2015/20/ revolucion-agraria-necesidad-historica 
Viteri, G. y Zambrano, E. (2016). Comercialización de arroz en Ecuador: Análisis de la evolución de precios en el eslabón productor-consumidor. Instituto Nacional de Investigaciones Agropecuarias INIAP, Revista Ciencias Agrarias, (p. 14). Recuperado de: http://dx.doi. org/10.18779/cytuteq.v9i2.21.g11

Zambrano, L. (07 de enero de 2020). La industria aspira a que el precio del maíz sea más bajo. Diario Expreso. Recuperado de: https://www.expreso.ec/actualidad/ economia/ industria-aspira-precio-maiz-sea-2859.html

\section{Cuerpos legales}

Agencia de Regulación y Control Fito y Zoosanitario. (2017) Resolución 41, Manual de Buenas Prácticas Agropecuarias. R.O. No. 1011 de 24 de mayo de 2017.

Constitución de la República del Ecuador [Const.]. (2008). (artículo 22). 2da Ed. CEP.

Asamblea Nacional del Ecuador. Ley Orgánica de Regulación y Control del Poder de Mercado. [Ley]. (13 de octubre de 2011). RO. 555 de 13 de octubre de 2011.

Presidente Constitucional de la República del Ecuador mediante Decreto Ejecutivo 1152. Reglamento a la Ley Orgánica de Regulación y Control del Poder de Mercado. [Reglamento]. RO. 697 de 07 de mayo de 2012.

Ministerio de Agricultura, Ganadería, Acuacultura y Pesca. Acuerdo Ministerial No. 134 "Reglamento de Comercialización del Maíz Amarillo Duro". [AM]. RO. 933 de 15 de abril de 2013.

Ministerio de Agricultura, Ganadería, Acuacultura y Pesca. Acuerdo Ministerial No. 394. [AM]. RO. 100 de 14 de octubre de 2013. 
Ministerio de Agricultura, Ganadería, Acuacultura y Pesca. Acuerdo Interministerial No. 001-2013. [AI]. RO. 100 de 14 de octubre de 2013.

Ministerio de Agricultura y Ganadería. Acuerdo Ministerial No. 69. [AM]. RO. 941 de 25 de abril de 2019.

Ministerio de la Producción, Comercio Exterior, Inversiones y Pesca. Acuerdo Interministerial No. 177. [AI]. RO. 91 de 29 de noviembre de 2019.

\section{Jurisprudencia}

Caso United States vs. Borden; y United States vs. Maryland \& Virginia Milk Producers Association. (19 de enero de 1960).

Recibido: $26 / 03 / 2020$

Aprobado: 12/06/2020

Christian Narváez Barrera : Investigador independiente. Abogado asociado de FERRERE Ecuador (equipo de Derecho Corporativo).

Correo electrónico: cnarvaez@ferrere.com

Antonella Cordero Porras: Investigadora Independiente Abogada asociada en FERRERE Ecuador (equipo de Litigios).

Correo electrónico: acordero@ferrere.com

Ciudad: Quito

País: Ecuador 
